\title{
Validation of an analytical method for determination of eight food dyes in beverage and fruit roll-ups by ion-pair HPLC-DAD
}

\begin{abstract}
Maryam Zahedi $^{\mathbb{D}}$, Amir Shakerian $^{2 *}{ }^{(\mathbb{D}}$, Ebrahim Rahimi $^{\mathbb{D}}$, Reza Sharafati Chaleshtori ${ }^{2,3}{ }^{(\mathbb{D}}$
'Department of Food Hygiene, Faculty of Veterinary Medicine, Shahrekord Branch, Islamic Azad University, Shahrekord, Iran. ${ }^{2}$ Research Center of Nutrition and Organic Products (R.C.N.O.P), Shahrekord Branch, Islamic Azad University, Shahrekord, Iran. ${ }^{3}$ Research Center for Biochemistry and Nutrition in Metabolic Disease, Kashan University of Medical Sciences, Kashan, Iran.

*Corresponding Author: Amir Shakerian, Research Center of Nutrition and Organic Products (R.C.N.O.P), Shahrekord Branch, Islamic Azad University, Shahrekord, Iran, Tel: +98-38-2244515, Email: amshakerian@yahoo.com, amshakerian@iaushk.ac.ir

Abstract

Background and aims: Synthetic dyes are widely used as food additives to avoid the loss of original dye in processed foods and to make the foods more attractive to consumers. For simultaneous determination of 8 most commonly used synthetic colors in beverage and foodstuff, an efficient, selective, and sensitive method is suggested.

Methods: To analyze food colors in different beverages and fruit roll-ups, a method using lon-pair high-performance liquid chromatography with diode array detector was suggested and validated. The separation of dyes from beverage and foodstuff was done by solid-phase extraction (SPE). The ultrasound-assisted solvent extraction method was used to extract dye from fruit roll-ups.

Results: The limit of detection and the limit of quantification ranged from 0.036 to 0.07 and 0.098 to $0.2 \mu \mathrm{g} / \mathrm{mL}$, respectively. IP-HPLCDAD method was validated using precision (RSD \%) and accuracy (Recovery \%) of two concentrations of 0.5 and $1 \mu \mathrm{g} / \mathrm{mL}$ in terms of intra- and inter-day. SPE method was also validated using intra- and inter-day precision and accuracy. The most commonly detected dye in the tested samples was carmoisine with a concentration of $386 \mu \mathrm{g} / \mathrm{g}$. Additionally, the concentration of dye was higher than the permitted level in $28.6 \%$ of beverages, $40 \%$ of edible ice products, and $100 \%$ of fruit roll-ups (Lavashak).

Conclusion: This method is an effective, appropriate, accessible, reliable and safe analytic method to analyze eight food dyes Keywords: Synthetic color, Beverage, Foodstuff, Solid phase extraction, HPLC
\end{abstract}

Received: 15 October 2019, Accepted: 15 January 2020, ePublished: 29 June 2020

\section{Introduction}

Synthetic colors are an important group of food additives. Food products with these kinds of colors are cheaper and more resistant to light, oxygen, and different $\mathrm{pH}$ values in comparison with food products with natural dyes. Their color also does not change in the long run. Therefore, producers might use synthetic colors, higher than the permitted levels, to make their food products more attractive (1). In most foods and beverages, mixtures of food colors are generally used to achieve normal colors. Therefore, it is required to expand an efficient method to control the amount allowable for use (2). Research has shown that food dyes and their metabolites could induce allergy, asthma, DNA damage, cancer, and attention deficit/hyperactivity disorder (3). Therefore, the analysis and examination of synthetic colors in foodstuffs could play a major role in promoting health and enhancing the quality of food products. Permitted synthetic color types and their concentration levels vary in different countries because of different insights into the safety of food products, but health authorities have announced the maximum permitted concentration of food colors in foods as acceptable daily intake (ADI) (4).

Based on Iranian National Standards (5), seven synthetic colors including, Sunset yellow (E110), Indigo carmine (E132), carmoisine (E122), quinoline yellow (E104), Ponceau 4R (E124), Allura red (E129), and brilliant blue (E133) are permitted to be used in food products. Although tartrazine (E102) is not permitted in Iran, it is often used in food products (6).

Different methods have been used to identify and quantify the concentration of the synthetic food colors in food products, for example thin-layer chromatography (7), adsorptive voltammetry (8), differential pulse polarography (9), and electrophoresis $(10,11)$. However, most of them are time-consuming and do not have the capability of separating dye from dye mixtures. Liquid chromatography is usually used for the differentiation and quantification of synthetic colors. Ion chromatography (12), ion-pair (IP) liquid chromatography $(13,14)$, and

(C) 2020 The Author(s); Published by Shahrekord University of Medical Sciences. This is an open-access article distributed under the terms of the Creative Commons Attribution License (http://creativecommons.org/licenses/by/4.0), which permits unrestricted use, distribution, and reproduction in any medium, provided the original work is properly cited. 
reversed-phase (RP) liquid chromatography $(15,16)$ are the preferred methods, as they provide higher resolution, sensitivity, and selectivity. Regarding sample preparation to analyze dye concentration, the method of dye extraction could be more complex than the method of analysis. The selection of the extraction method is based on the sample matrix and the analytic method used to separate (17). One of the most common methods for pre-concentration, extraction and cleaning-up of both organic and inorganic compounds from a variety of foods and other samples is solid phase extraction (SPE) because this method has many advantages such as easiness and high speed (18). Appropriate solvents should be used before dye extraction by SPE method for solid samples (3).

The main purpose of this article was to develop and validate a practical, selective, simple, and sensitive method for screening eight food colors in a single run that could be applied in food control laboratories. Additionally, SilactSPE ${ }^{\mathrm{TM}} \mathrm{C}_{18}$ was used for color extraction.

\section{Materials and Methods \\ Chemical and reagent \\ Color standards}

Standards for the eight colors under study including Sunset yellow, indigo carmine, Carmoisine (Azorobin), Quinoline yellow, Ponceau 4R, Allura red, Brilliant blue, and tartrazine were obtained from Iranian Food and Drug Administration. All data about these colors, including name, chemical structure, molecular weight, European Union E number, US FDA code, appearance, and ADI are shown in Table 1. To prepare the stock solution for each dye, a standard of $200 \mathrm{mg} / \mathrm{L}$ was separately provided and kept at $5^{\circ} \mathrm{C}$. The working standard solutions and mixed solutions were provided by dilution of stock solutions with deionized water.

\section{Preparation of SPE cartridge and samples} Preparation of SPE

The solid-phase extraction (SilactSPE ${ }^{\mathrm{TM}} \mathrm{C}_{18}$ ) was

Table 1. Common Name, Chemical Structure, Appearance, Molecular Weight (MW), European

\begin{tabular}{|c|c|c|c|c|c|c|}
\hline Common name & Chemical structure & Appearance & MW (kg) & EC & FD \& C & $\mathrm{ADI}(\mathrm{mg} / \mathrm{kg} \mathrm{bw} / \mathrm{d})$ \\
\hline Tartrazine & & Yellow powder & 534.36 & E102 & - & 7.5 \\
\hline Indigo carmine & & Purple solid & 466.35 & E132 & Blue 2 & 5 \\
\hline Ponceau 4R & & Red powder & 604.46 & E124 & Red 7 & 4 \\
\hline Quinoline yellow & & $\begin{array}{c}\text { Greenish yellow } \\
\text { powder }\end{array}$ & 477.38 & E104 & 101 & 5 \\
\hline Sunset yellow FCF & & $\begin{array}{l}\text { Red orange } \\
\text { powder }\end{array}$ & 452.37 & E110 & Yellow 6 & 4 \\
\hline Allura red $\mathrm{AC}$ & & Red powder & 496.42 & E129 & Red 40 & 7 \\
\hline Carmoisine (Azorbin) & & Red powder & 502.44 & E122 & - & 4 \\
\hline Brilliant blue & & Blue powder & 792.85 & E133 & Blue 1 & 12.5 \\
\hline
\end{tabular}

Community (EC), Food, Drug \& Cosmetic (FD \& C ), Acceptable Daily Intake (ADI) of 8 Synthetic Color 
continuously conditioned with $2 \mathrm{~mL}$ of isopropyl alcohol and $5 \mathrm{~mL}$ of acetic acid. When the reagent was removed, the cartridge was ready for use. The treatment described was repeated after the application of the sample to the cartridge (13).

\section{Liquid samples}

After conditioning of the cartridges, $3.0 \mathrm{~mL}$ of the degassed and homogenized samples was passed through them. The aqueous fraction containing sugars was removed, leaving only the solid phase behind which was extracted with a $10.0 \mathrm{~mL}$ solution of $18 \%(\mathrm{v} / \mathrm{v})$ isopropyl alcohol. The alcoholic solutions containing the color compound were placed in a rotary evaporator with vacuum. Subsequently, complete evaporation of a dry food coloring was obtained, $3.0 \mathrm{~mL}$ of water was added to them and the samples were transferred to glass vials to be filtered through a $0.45 \mu \mathrm{m}$ PTFE hydrophilic membrane (Q-Max). Then, they were placed in vials for injection into the liquid chromatograph and for application on the chromatography plates (13).

Solid samples

Fruit roll-ups (lavashak) were solid samples in this study. They were water-soluble but the dye used in them was not separable in the liquid phase. To do so, $5 \mathrm{~g}$ of fruit roll-ups was weighed into a falcon tube and $30 \mathrm{~mL}$ of solvent (methanol/ammonium hydroxide 20:80) was added. The tube was placed in an ultrasound bath for 20 minutes to dissolve the sample. Then, the solution was stirred and centrifuged using a centrifuge at $4000 \mathrm{rpm}$ for 5 minutes. The centrifugal step was repeated twice more, each time with an addition of $10 \mathrm{~mL}$ of methanol/ ammonium hydroxide, in order to extract the maximum possible amount of colors from the samples. After each centrifugation, the fractions were collected and transferred to a $100 \mathrm{~mL}$ volumetric flask and its volume was topped up with the above-mentioned solvent. Finally, $3 \mathrm{~mL}$ of the clear part was passed through SPE cartridge. The rest of the procedure was the same as that of separation of liquid solutions (1).

\section{IP-HPLC-DAD method}

An Agilent 1090 HPLC system with a quaternary pump was used for the liquid chromatography analysis. A Phenomenex C18 column $(250 \mathrm{~mm} \times 3 \mathrm{~mm} 4 \mu \mathrm{m})$ was selected and thermostated at $40^{\circ} \mathrm{C}$. The mobile phase consisted of $\mathrm{CH} 3 \mathrm{COONH} 4(0.08 \mathrm{~mol} / \mathrm{L}, \mathrm{pH}=6)$ as the solvent and acetonitrile-methanol-deionized water (25:25:50 V/V) as component B. Linear gradient elution program was used $(5 \% \mathrm{~A}$ at start; linear to $100 \% \mathrm{~B}$ in 20 minutes). The flow was fixed at $0.5 \mathrm{~mL} / \mathrm{min}$. Final samples were injected onto the column with $20 \mu \mathrm{L}$ volume. The column was re-equilibrated for 15 minutes using component A between subsequent analyses. Moreover, Chem Station software was used for the analysis of the data.
In order to determine the best wavelength to identify the dyes, a UV-VIS spectrophotometer with a wavelength range of 200-900 $\mathrm{nm}$ was used. The concentration of 5 $\mu \mathrm{g} / \mathrm{mL}$ of colors was considered for this step (Figure 1). For quantitative and qualitative recognition of analytes, five different wavelengths (413 and $427 \mathrm{~nm}$ for yellow colors, 505 and $515 \mathrm{~nm}$ for red colors and $630 \mathrm{~nm}$ for blue colors) were considered. The identification of colors was done based on retention time and also the comparison between different peaks of standard colors in UV-VIS and peaks of samples that were identified by UV.

\section{Validation of IP-HPLC-DAD method}

The calibration curve of colors was sketched based on the concentration of colors and area under the peaks. Standards of the colors were prepared in deionized water for the concentration range of $0.05-2.5 \mu \mathrm{g} / \mathrm{mL}$ and injected three times into instrument in the same condition. The curves of the standard during the study were properly linear and the correlation between concentration and area under peak was found to be $\mathrm{R}^{2}>0.9991$. Based on ICH guidelines (19), the instrumental limit of detection (LOD) and limit of quantification (LOQ) for all analytes were computed using the following formulae:

$$
\begin{aligned}
& L O D=3.3 \frac{\mathrm{SD}}{\mathrm{S}} \\
& L O Q=10 \frac{\mathrm{SD}}{\mathrm{S}}
\end{aligned}
$$
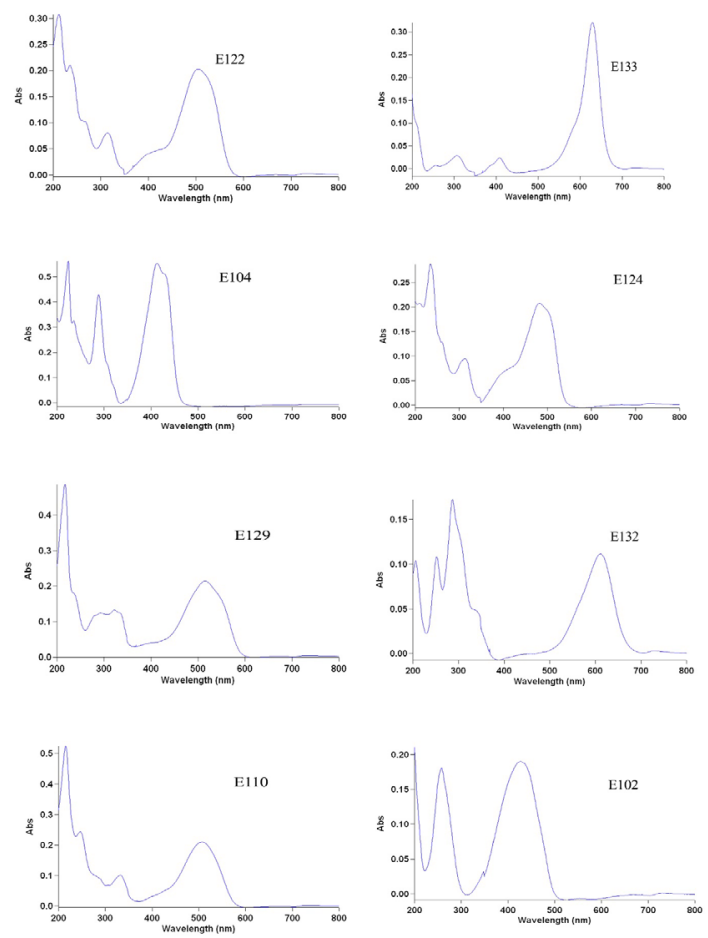

Figure 1. UV-VIS spectra of 8 synthetic food colors collected from individual solution $(5 \mu \mathrm{g} / \mathrm{mL})$. 
Where SD is the standard deviation of Y-intercept of regression lines (computed using LINEST function in MS EXEL 2013) and $S$ is the slope of the calibration plot. IP-HPLC-DAD instrument was also validated in terms of intra and inter-day precision and accuracy. Two concentrations of 0.5 and $1 \mu \mathrm{g} / \mathrm{mL}$ were chosen. Three mixtures of the standards of colors for each concentration were provided and analyzed for three consecutive days. The average concentration was calculated for each of the concentrations and precision, accuracy, and standard deviation were estimated based on the data.

\section{Validation of samples preparation method}

Validation of SPE was done using SilactSPE ${ }^{\mathrm{TM}} \mathrm{C}_{18}$ cartridge. The precision and accuracy were verified by analyzing samples over a few days by three intra-day repetitions and analytes were also tested for three consecutive days. In this way, precision and accuracy were verified for one day $(n=9)$. The accuracy level was also calculated by the following formula:

$$
\text { Re cov ery } \%=\frac{\text { Average analyte concentration found in the sample }}{\text { Analyte concentration added to the sample }} \times 100
$$

Accuracy level was determined by calculation of RSD \% using the following formula

$\% R S D=\frac{\text { SD of recovery }}{\text { Mean Recovery }} \times 100$

Mixture of the eight colors under study, with a concentration of $2 \mu \mathrm{g} / \mathrm{mL}$ was provided and passed through the prepared column of SPE and then precision and accuracy were calculated by formula 3 and 4 . Due to the use of ultrasound assisted extraction method (UAE) for separation of colors from fruit roll-ups (lavashak), the validation method was performed with three spiked concentration $(20,50$ and $100 \mu \mathrm{g} / \mathrm{mL}$ ) of detected colors considering the type of the identified dye in each product and the results were analyzed.

\section{Results}

\section{Validation of IP-HPLC-DAD method}

Identification of eight synthetic colors by the gradient elution method was possible in less than 20 minutes. It revealed satisfactory selectivity and symmetry of peaks for all of colors. All peaks were slender with widths at their half-height ranging from 0.1 to 0.23 and symmetry factor (As) ranging from 0.449 to 0.873 (Figure 2 and Table 2). All these results corroborated that chromatographic system applied in this study is suitable and show satisfactory efficiency for the analysis of synthetic colors.

IP-HPLC-DAD, the research method used to separate colors under study, revealed a satisfactory sensitivity. Based on LINEST function in Excel, LOD and LOQ of the colors ranged from 0.032 to $0.07 \mu \mathrm{g} / \mathrm{mL}$ and 0.098 to 0.2 $\mu \mathrm{g} / \mathrm{mL}$, respectively (Table 3 ).

Validation of the suggested method for colors identification with IP-HPLC-DAD was done in terms of inter- and intra-days precision and accuracy. Interday precision and accuracy (RSD \%) were calculated for two concentrations of 0.5 and $1 \mu \mathrm{g} / \mathrm{mL}$ of standard solution with three different samples per day during three consecutive days (Table 4). Inter-day precision and accuracy for the concentration of $1 \mu \mathrm{g} / \mathrm{mL}$ ranged from 92.24 to 106.53 and 0.38 to 0.88 on the first day, 91.09 to 107.67 and 0.28 to 0.88 on the second day, 91.51 to 108.77 and 0.34 to 0.89 on the third day, respectively. Inter-day precision and accuracy for the concentration of $0.5 \mu \mathrm{g} / \mathrm{mL}$ ranged from 88.78 to 110.24 and 0.51 to 1.83 on the first day, 89.08 to112.26 and 0.41 to 1.91 on the second day, 90.5 to 113.2 and 0.31 to 1.70 on the

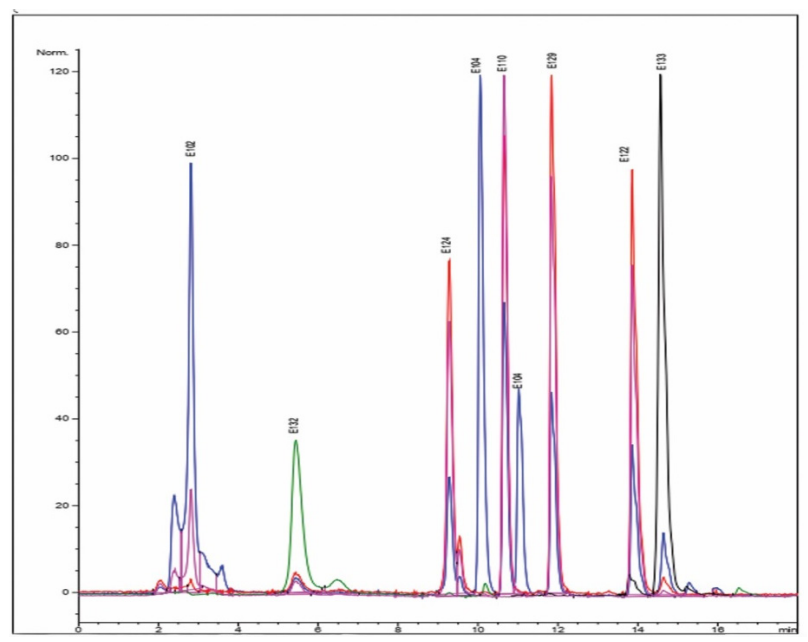

Figure 2. Chromatogram showing separation of 8 food synthetic colors at concentration of $2 \mu \mathrm{g} / \mathrm{mL}$ (overlaid signals from 427,482,515 and $630 \mathrm{~nm}$ wavelengths).

Table 2. Chromatographic Parameters (based on Figure 2) for Individual Peaks (k: capacity factor, $W_{50}(\min )$ : Peak Width at Half Height, $\alpha$ : Selectivity to Proceeding Peak, Rs: Resolution to Proceeding Peak Calculated by Half Width Method, As: Symmetry Factor)

\begin{tabular}{lccccccccc}
\hline E number & E102 & E132 & E124 & E104* & E110 & E104** & E129 & E122 & E133 \\
\hline K & 0.14 & 1.4 & 2.94 & 3.24 & 3.49 & 3.64 & 3.97 & 4.84 & 5.15 \\
$W_{50}(\min )$ & 0.13 & 0.23 & 0.15 & 0.10 & 0.11 & 0.12 & 0.14 & 0.15 \\
$\alpha$ & - & 10 & 2.1 & 1.1 & 1.08 & 1.04 & 1.09 & 1.19 & 1.06 \\
Rs & - & 10.1 & 11.4 & 3.25 & 3.36 & 2.04 & 3.16 & 8.75 \\
As & 0.496 & 0.611 & 0.873 & 0.7 & 0.734 & 0.792 & 0.537 & 0.449 \\
\hline
\end{tabular}

). All parameters were calculated by ChemStation software.

*The first peak of Quinoline yellow

**The second peak of Quinoline yellow 
Table 3. Results of the analytical curves [Retention time $\left(t_{\mathrm{R}}\right)$, Wavelength $(\lambda)$, correlation coefficient $\left(R^{2}\right)$, linear regression, limit of detection $(L O D)$ and limit of quantitation (LOQ)] for 8 synthetic colors using IP-HPLC-DAD

\begin{tabular}{|c|c|c|c|c|c|c|}
\hline \multirow{2}{*}{ Name } & \multirow{2}{*}{$t_{R(\min )}$} & \multicolumn{5}{|c|}{ Calibration data } \\
\hline & & $\lambda(\mathrm{nm})$ & $\mathbf{R}^{2}$ & Linear regression & LOD $(\mu \mathrm{g} / \mathrm{mL})$ & LOQ $(\mu \mathrm{g} / \mathrm{mL})$ \\
\hline Tartrazine & 2.7 & 427 & 0.9996 & $y=55.263 x+1.2683$ & 0.047 & 0.14 \\
\hline Indigo carmine & 5.8 & 630 & 0.9998 & $y=65.482 x-2.6602$ & 0.032 & 0.098 \\
\hline Ponceau 4R & 9.5 & 505 & 0.9994 & $y=59.019 x-1.1498$ & 0.058 & 0.18 \\
\hline Quinoline yellowa & $\begin{array}{l}10.2 \\
11.1\end{array}$ & 413 & 0.9997 & $y=68.33 x+1.1320$ & 0.043 & 0.13 \\
\hline Sunset yellow FCF & 10.8 & 482 & 0.9998 & $y=83.598 x+0.8877$ & 0.036 & 0.11 \\
\hline Allura red $A C$ & 11.9 & 505 & 0.9996 & $y=87.733 x+1.7020$ & 0.049 & 0.15 \\
\hline Carmoisine (Azorbin) & 14.06 & 515 & 0.9996 & $y=83.669 x+1.6267$ & 0.047 & 0.14 \\
\hline Brilliant blue & 14.8 & 630 & 0.9991 & $y=119.49 x+3.9158$ & 0.07 & 0.2 \\
\hline
\end{tabular}

${ }^{a}$ Quinolone Yellow has 2 peak at two different time (10.2 and $\left.11.1 \mathrm{~min}\right)$.

Table 4. Intra and Inter-day Accuracy and Precision Studied for the Proposed IP-HPLC-DAD Method at 1 and $0.5 \mu \mathrm{g} / \mathrm{mL}$ Concentrations

\begin{tabular}{|c|c|c|c|c|c|c|c|c|c|}
\hline \multirow{3}{*}{ Color } & \multirow{3}{*}{$\begin{array}{l}\text { Con. } \\
(\mu \mathrm{g} / \mathrm{mL})\end{array}$} & \multicolumn{6}{|c|}{ Intra-day } & \multicolumn{2}{|c|}{ Inter-day $(n=9)^{b}$} \\
\hline & & \multicolumn{2}{|c|}{ Day $1(n=3)^{a}$} & \multicolumn{2}{|c|}{ Day $2(n=3)$} & \multicolumn{2}{|c|}{ Day $3(n=3)$} & \multirow[b]{2}{*}{$\begin{array}{c}\text { Accuracy } \\
(\%)\end{array}$} & \multirow[b]{2}{*}{$\begin{array}{l}\text { Precision } \\
\text { (RSD \%) }\end{array}$} \\
\hline & & $\begin{array}{c}\text { Accuracy } \\
(\%)^{c}\end{array}$ & $\begin{array}{l}\text { Precision } \\
\left(^{(R S D \%}\right)^{d}\end{array}$ & $\begin{array}{c}\text { Accuracy } \\
(\%)\end{array}$ & $\begin{array}{l}\text { Precision } \\
\text { (RSD \%) }\end{array}$ & $\begin{array}{c}\text { Accuracy } \\
(\%)\end{array}$ & $\begin{array}{c}\text { Precision } \\
\text { (RSD \%) }\end{array}$ & & \\
\hline \multirow{2}{*}{ Tartrazine } & 1 & 92.24 & 0.70 & 91.09 & 0.60 & 91.51 & 0.52 & 91.61 & 0.62 \\
\hline & 0.5 & 99.18 & 1.83 & 92.18 & 1.78 & 95.46 & 1.36 & 95.60 & 3.66 \\
\hline \multirow{2}{*}{ Indigo Carmine } & 1 & 96.92 & 0.88 & 96.21 & 0.88 & 95.70 & 0.89 & 96.28 & 0.63 \\
\hline & 0.5 & 88.78 & 1.04 & 89.08 & 1.23 & 90.50 & 1.70 & 89.46 & 1.03 \\
\hline \multirow{2}{*}{ Ponceau 4R } & 1 & 95.93 & 0.81 & 96.43 & 0.53 & 96.21 & 0.54 & 96.19 & 0.26 \\
\hline & 0.5 & 101.48 & 0.51 & 99.45 & 1.04 & 101.04 & 0.67 & 100.66 & 1.05 \\
\hline \multirow{2}{*}{ Quinoline yellow } & 1 & 104.11 & 0.51 & 103.74 & 0.48 & 104.68 & 0.64 & 104.18 & 0.45 \\
\hline & 0.5 & 109.72 & 1.73 & 112.26 & 0.53 & 111.32 & 1.20 & 111.1 & 1.15 \\
\hline \multirow{2}{*}{ Sunset yellow FCF } & 1 & 98.91 & 0.8 & 100.85 & 0.74 & 100.49 & 0.59 & 100.09 & 0.99 \\
\hline & 0.5 & 106.56 & 1.01 & 103.7 & 1.91 & 106.32 & 1.28 & 105.52 & 0.43 \\
\hline \multirow{2}{*}{ Allura red $\mathrm{AC}$} & 1 & 106.3 & 0.54 & 107.67 & 0.64 & 108.77 & 0.52 & 107.61 & 1.02 \\
\hline & 0.5 & 110.24 & 1.25 & 110.7 & 1.53 & 110.56 & 1.46 & 110.50 & 0.18 \\
\hline \multirow{2}{*}{ Carmoisine (Azorbin) } & 1 & 106.53 & 0.45 & 105.74 & 0.45 & 105.38 & 0.34 & 105.88 & 0.56 \\
\hline & 0.5 & 106.78 & 1.01 & 108.68 & 1.10 & 108.06 & 1.33 & 107.84 & 0.91 \\
\hline \multirow{2}{*}{ Brilliant blue } & 1 & 102.89 & 0.28 & 102.89 & 0.28 & 103.22 & 0.71 & 103.54 & 0.82 \\
\hline & 0.5 & 107.3 & 0.41 & 107.30 & 0.41 & 108.24 & 0.31 & 108.10 & 0.68 \\
\hline
\end{tabular}

${ }^{a}$ Three different samples analyzed per day for intra-day accuracy and precision.

${ }^{\mathrm{b}} \mathrm{n}=9$ ( 3 days with three replicates per day).

${ }^{c}$ Calculated as $\frac{\text { Mean determind concentration }}{\text { Normal concentration }} \times 100$

d expressed as $R S D \%=\frac{\mathrm{SD}}{\text { Mean }} \times 100$

third day, respectively. Intra-day precision and accuracy (three times per day for three consecutive days) ranged from 61.96 to 107.61 and 0.26 to 1.02 for $1 \mu \mathrm{g} / \mathrm{mL}$ concentration as well as 89.46 to 111.1 and 0.43 to 3.66 for $0.5 \mu \mathrm{g} / \mathrm{mL}$ concentration, respectively. In this way, the method under study revealed an acceptable precision and accuracy for evaluating the amount of synthetic colors in drinks and food products.

Evaluation of the amount of colors in the real samples IP-HPLC-DAD method and sample preparation to analyze food products (including carbonated drinks, fruit roll-ups (lavashak), and ice products) were successfully performed. Five out of eight colors under study, including Sunset yellow ( 41 to $180 \mu \mathrm{g} / \mathrm{mL}$ ), Carmoisine (3.6 to 386 $\mu \mathrm{g} / \mathrm{mL}$ or $\mu \mathrm{g} / \mathrm{g}$ ), Quinoline (30 to $130 \mu \mathrm{g} / \mathrm{mL}$ or $\mu \mathrm{g} / \mathrm{g}$ ), Brilliant blue ( 0.5 to $10 \mu \mathrm{g} / \mathrm{mL}$ or $\mu \mathrm{g} / \mathrm{g}$ ), and Allura red $(10 \mu \mathrm{g} / \mathrm{mL})$ were detected in the samples, but three colors of tartrazine, Ponceau $4 \mathrm{R}$, and indigo carmine were not detected in any of the samples. Details of the amounts of colors in the samples were shown in Table 5.

\section{Validation of samples preparation method}

SPE protocol was validated using mixed colors solution, 
containing $2 \mu \mathrm{g} / \mathrm{mL}$ of each dye. Results of inter and intraday repetitions are depicted in Table 6 . Intra-day precision (recovery \%) and accuracy (RSD \%) for three samples per day ranged from 89.7 to 102.7 and 2.2 to 5.2 on the first day, 90 to 100.7 and 2.1 to 4.5 on the second day, 90,7 to 104.7 and 2 to 4.9 on the third day, respectively. These parameters were also calculated over a period of 3 days with three replicates per day $(n=9)$, which ranged from 90.1 to 104.4 and 0.92 to 3.9, respectively. Given the use of only SPE in the steps of preparation of liquid samples for extraction and purification of dye, there was no need for additional recovery in this method. In this way, the calculated recovery depicted in Table 6 could be applied to liquid samples.

Validation of the detected colors of brilliant blue, carmoisine, and quinoline yellow in fruit roll-ups (lavashak) was done. Recovery\% and RSD\% ranged from 90.1 to 93.2 and 3.2 to 6.3 for Brilliant blue, from 94.7 to 101.7 and 3.1 to 6.1 for carmoisine, and from 93.8 to 99.1 and 2.3 to 5.1 for quinoline, respectively (Table 7 ).

Table 5. The Amount of Synthetic Colors in Real Samples

\begin{tabular}{|c|c|c|c|c|}
\hline Sample code & Sample type & Labeled dye & Detected dye & Average concentration $(\mu \mathrm{g} / \mathrm{mL})$ or $(\mu \mathrm{g} / \mathrm{g})^{* *}$ \\
\hline S1 & $\begin{array}{l}\text { Edible ice products } \\
\text { (Red) }\end{array}$ & Permitted food color* & E122 & $19.03 \pm 2.4$ \\
\hline S2 & $\begin{array}{l}\text { Edible ice products } \\
\text { (Red) }\end{array}$ & Permitted food color & $\begin{array}{l}\mathrm{E} 122 \\
\mathrm{E} 110\end{array}$ & $\begin{array}{c}30.1 \pm 2.9 \\
5 \pm 0.9\end{array}$ \\
\hline S3 & $\begin{array}{l}\text { Edible ice products } \\
\text { (Red) }\end{array}$ & Permitted food color & E122 & $144 \pm 8.1$ \\
\hline S4 & $\begin{array}{l}\text { Edible ice products } \\
\text { (Orange) }\end{array}$ & Permitted food color & E110 & $41 \pm 4$ \\
\hline S5 & $\begin{array}{c}\text { Edible ice products } \\
\text { (Yellow) }\end{array}$ & Permitted food color & E104 & $92 \pm 6.5$ \\
\hline S6 & Carbonated drink & E110 & E110 & $75.6 \pm 2.8$ \\
\hline S7 & Carbonated drink & E110 & E110 & $67.5 \pm 4.4$ \\
\hline S8 & Carbonated drink & E122 & E122 & $38 \pm 3.1$ \\
\hline S9 & Carbonated drink & E104, E133 & $\begin{array}{l}\mathrm{E} 104 \\
\mathrm{E} 133\end{array}$ & $\begin{array}{c}9.6 \pm 1.4 \\
0.2 \pm 0.11\end{array}$ \\
\hline S10 & Carbonated drink with fruit juice & E104, E133 & $\begin{array}{l}\mathrm{E} 104 \\
\mathrm{E} 133\end{array}$ & $\begin{array}{c}31.8 \pm 3 \\
0.5 \pm 0.17\end{array}$ \\
\hline S11 & Carbonated drink with fruit juice & E133, E129 & $\begin{array}{l}\mathrm{E} 104 \\
\mathrm{E} 129\end{array}$ & $\begin{array}{l}20 \pm 3.7 \\
32.5 \pm 4\end{array}$ \\
\hline S12 & Carbonated drink with red grape juice & Anthocyanin & E122 & $3.6 \pm 0.64$ \\
\hline S13 & Fruit roll-ups (lavashak) & - & $\begin{array}{l}\mathrm{E} 104 \\
\mathrm{E} 122\end{array}$ & $\begin{array}{c}51.6 \pm 4.9 \\
130 \pm 3.4\end{array}$ \\
\hline S14 & Fruit roll-ups (lavashak) & - & $\begin{array}{l}\mathrm{E} 104 \\
\mathrm{E} 133\end{array}$ & $\begin{array}{l}286 \pm 4 \\
10 \pm 1.5\end{array}$ \\
\hline S15 & Fruit roll-ups (lavashak) & - & E122 & $386 \pm 6.1$ \\
\hline S16 & Fruit roll-ups (lavashak) & - & E122 & $270 \pm 5.3$ \\
\hline
\end{tabular}

*Not declared the name or number of dyes

Table 6. Intra and inter-day accuracy (recovery \%) and precision ( $r s d \%$ ) for mixture of 8 synthetic dyes extracted by SPE from $10 \mathrm{~mL}$ of water containing $2 \mu \mathrm{g}$ of each dye standard

\begin{tabular}{|c|c|c|c|c|c|c|c|c|}
\hline \multirow{3}{*}{ Dyes } & \multicolumn{6}{|c|}{ Intra-day } & \multicolumn{2}{|c|}{$\begin{array}{c}\text { Inter-day } \\
(\mathbf{n}=9)\end{array}$} \\
\hline & \multicolumn{2}{|c|}{ Day $1(n=3)$} & \multicolumn{2}{|c|}{ Day $2(n=3)$} & \multicolumn{2}{|c|}{ Day $3(n=3)$} & \multirow[b]{2}{*}{ Recovery (\%) } & \multirow[b]{2}{*}{ RSD ( \% } \\
\hline & Recovery (\%) & RSD (\%) & Recovery (\%) & RSD (\%) & Recovery (\%) & RSD (\%) & & \\
\hline Tartrazine & 89.7 & 2.8 & 90 & 3.3 & 90.7 & 4.9 & 90.1 & 3.7 \\
\hline Indigo carmine & 97.3 & 2.2 & 98.3 & 4.1 & 98 & 2.04 & 97.9 & 2.8 \\
\hline Ponceau 4R & 98.3 & 5.2 & 95 & 3.1 & 96.7 & 3.3 & 96.7 & 3.9 \\
\hline Quinoline yellow & 100.2 & 2.6 & 100.2 & 3.5 & 100 & 2 & 101.2 & 2.7 \\
\hline Sunset yellow FCF & 99.7 & 2.5 & 100.7 & 2.1 & 100 & 4.2 & 100.2 & 2.9 \\
\hline Allura red $\mathrm{AC}$ & 102.7 & 2.9 & 106 & 3.4 & 104.7 & 3.6 & 104.4 & 3.3 \\
\hline Carmoisine (Azorbin) & 99 & 2.7 & 98 & 1.02 & 100.3 & 2.4 & 99.11 & 2.1 \\
\hline Brilliant blue & 99.9 & 2.7 & 99.3 & 4.5 & 100.2 & 3.9 & 100.4 & 0.92 \\
\hline
\end{tabular}




\section{Discussion}

Expansion and validation of IP-HPLC-DAD and SPE method

One of the separation techniques and quantitative and qualitative determination of synthetic food colors is HPLC. Separation in this technique is based on the difference in affinity of components to two mobile and stationary phases. Colors have different absorption rates in the stationary phase based on their molecular weight, spatial structure, and their main groups so that colors with more naphthalene rings in their structure have more retention time in comparison with colors containing more benzene rings. Reverse-phase and ion-pair complementary are the most commonly used HPLC methods. In IP-HPLC method, a hydrophobe ionic material is added to the mobile phase which is produced by the reaction between the sample and inert ionic eluent and then separation is done by reversed phase system. In some materials due to the absence of ionic compositions, elution through the column for some colors such as indigo carmine, Ponceau $4 \mathrm{R}$, and tartrazine happens very fast and close to the dead volume. Adding ionic compositions will considerably increase the inhibition time in molecules with acid groups. This leads to the simultaneous separation of different colors. To do so, ammonium acetate buffer is used. Another advantage of using ammonium acetate in the mobile phase is to increase the efficiency of the chromatography system and improve the shape of peaks (17). Organic solvents are used in most of the liquid chromatography methods, which have negative effects on human beings and the environment. Accordingly, in this study, we have tried to decrease the use of organic solvents as much as possible and to use mobile phase water instead of it. In most liquid chromatography methods of separation of synthetic colors, the dye is separated from food products first and then after purification, it is injected into the device for analysis (17). Nowadays, SPE is an efficient method of extraction and purification and the main goal of its use is to diminish the problems of the sample matrix. Different adsorbents have been designed for the separation of dye from food products based on SPE. SilactSPE ${ }^{\mathrm{TM}} \mathrm{C}_{18}$ is a non-organic, strong, hydrophobe, and non-polar adsorbent which is appropriate for the extraction of acidic and neutral compositions from water solutions (20).

HPLC-DAD method for separation of colors studied showed acceptable sensitivity. The level of LOD and LOQ ranged from 0.32 to 0.07 and 0.098 to $0.2 \mu \mathrm{g} /$ $\mathrm{mL}$, respectively, according to the LINEST program. This concentration range is seen in several other studies that have done the same procedure $(21,22)$. This level of detection is lower compared to some of the studies performed by HPLC-DAD. In a study, Zamani Mazdeh et al separated 8 synthetic colors by reverse chromatography in which the LOD and LOQ ranged from 0.357 to 0.873 and 1.082 to $2.646 \mathrm{mg} / \mathrm{kg}$, respectively, which were higher compared with the current study. Floriano et al reported 0.15 and $1.154 \mathrm{mg} / \mathrm{L}$ for LOD and LOQ, respectively, for synthetic colors in sport drinks using RP-HPLC, which are higher compared with the current study $(23,24)$. Feng et al have reported higher LOD for tartrazine and Ponceau $4 \mathrm{R}$ colors as well as lower LOD for Indigo, Sunset yellow, Allura red, Quinoline yellow, Brilliant blue, and Carmoisine compared with our study (25). Some studies have also provided lower LOD and LOQ values compared to our study $(22,26)$.

\section{Evaluation of the amount of colors in the samples}

Preparation of different liquid samples (carbonated drinks and edible ice products) and solid samples (fruit roll-ups, lavashak) was done using SilactSPE ${ }^{\mathrm{TM}} \mathrm{C}_{18}$. In this study, the colors were separated from fruit roll-ups using UAE and determined using IP-HPLC-DAD for the first time in the world. This method showed acceptable separation and sensitivity in this foodstuff. The use of synthetic colors is prohibited by Iranian National Standard number 3308 (27). Therefore, all samples (100\%) of fruit roll-ups (lavashak) contained food colors with concentrations ranging from 10 to $386 \mu \mathrm{g} / \mathrm{g}$. Amini et al conducted a study on pasty

Table 7. Recovery and RSD of 3 Food Dyes [Carmoisine (E122), Quinolone yellow (E104) and Brilliant blue (E133)] spiked at 3 levels (20, 50\&100 $\mu$ g/mL) to Fruit Roll-ups (lavashak)

\begin{tabular}{|c|c|c|c|c|c|c|c|}
\hline \multirow{2}{*}{ Sample code } & \multirow{2}{*}{$\mathrm{C}$ added $(\mu \mathrm{g} / \mathrm{mL})$} & \multicolumn{2}{|c|}{ E104 } & \multicolumn{2}{|c|}{ E122 } & \multicolumn{2}{|c|}{ E133 } \\
\hline & & Recovery (\%) & RSD (\%) & Recovery (\%) & RSD (\%) & Recovery (\%) & RSD (\%) \\
\hline \multirow{3}{*}{ S13 } & 20 & 99.1 & 4.8 & 94.7 & 5.5 & - & - \\
\hline & 50 & 97.8 & 2.3 & 95.5 & 4.6 & - & - \\
\hline & 100 & 96.1 & 4.7 & 96.3 & 3.1 & - & - \\
\hline \multirow{3}{*}{ S14 } & 20 & 97.8 & 5.1 & - & - & 93.2 & 5.6 \\
\hline & 50 & 95.9 & 3.2 & - & - & 90.1 & 6.2 \\
\hline & 100 & 93.8 & 4.1 & - & - & 90.8 & 3.2 \\
\hline \multirow{3}{*}{ S15 } & 20 & - & - & 101.7 & 6.1 & - & - \\
\hline & 50 & - & - & 98.6 & 4.2 & - & - \\
\hline & 100 & - & - & 97.8 & 4.6 & - & - \\
\hline
\end{tabular}


products, fruit roll-ups, jelly powder, and beverages to investigate the Carmoisine color spectrophotometrically in all samples of fruit roll-ups (lavashak) and beverages and reported the presence of this color. The samples used in this study were red in color, the reason for which is the closeness of Carmoisine to the natural colors of cherries and plum (28). Additionally, in a study by Mohammadi et al on the traditionally prepared juices and fruit products in Tehran, colorants of cherry juice, wild plum, and barberry juice were most commonly reported (29).

The concentration of colors in two samples $(40 \%)$ of edible ice products, with higher levels of dye, ranged from 19.1 to $144 \mu \mathrm{g} / \mathrm{mL}$, which was higher than the maximum permitted concentration $(50 \mu \mathrm{g} / \mathrm{mL})$ based on Iranian National Standards (30).

Based on EU Regulation (EC) NO 94/36 (31), the maximum permitted amount of Sunset yellow, carmoisine, and Ponceau $4 \mathrm{R}$ in carbonated drinks is $50 \mu \mathrm{g} / \mathrm{mL}$. However, it was higher than the permitted level in two of the samples (28.6\%).

According to the results of food analysis, carmoisine was the most commonly used synthetic colors (50\%) followed by Quinoline yellow (37.5\%), Sunset yellow (25\%), Brilliant blue (18.7\%), and Allura red (6\%). Rao et al reported that the most commonly consumed food color in beverages was Sunset yellow (32\%) and the least commonly consumed dye was Brilliant blue (17\%) (32), however, Lok et al reported in their research on food products in Hong Kong that the most commonly consumed dye was Sunset yellow, mainly due to the consumption of dessert, jelly, and beverages (33).

\section{Conclusion}

In this study, we suggested an effective, appropriate, accessible, reliable, and safe analytic method to analyze eight food colors. Considering the low level of LOD and LOQ in IP-HPLC-DAD method, it is possible to evaluate different samples and different kinds of fruit roll-ups (lavashak). The use of ultrasound-assisted solvent extraction method to extract and the use of SPE to purify and condensate, associated with Ion-Pair separation method, was an effective way to separate dye from fruit roll-ups (lavashak). Repeatability and recovery of this method were appropriate to separate dye from different drinks, edible ice products, and fruit roll-ups. The amount of colors in $100 \%$ of the fruit roll-ups, $40 \%$ of edible ice products, and $26.8 \%$ of carbonated drinks was higher than Institute of Standards and Industrial Research of Iran (ISIRI) and European Union standards, respectively. Moreover, Carmoisine was the most commonly used synthetic colors.

Considering the fact that the acceptable method for evaluation of dye in food products in Iran is thin layer chromatography, which is a qualitative method and is not capable to measure the amount of colors, and regarding the importance of the amount of these colors in different food products, especially different beverages and snacks which are children's most favorite food, this study could be used to set new standards to measure the amount of colors and determine their level in food products.

Conflict of Interests

The authors declare that they have no conflict of interest.

Ethical Approval

This study protocol was approved by the Ethics Committee of Islamic Azad University of Shahrekord (IR- IAU.SHK.REC.1398.052) dated 1398.11.6.

Authors' Contributions

$M Z, A M:$ designed the study, carried out data collection.

$M Z, E R, R S H$ : participation in analysis and carried out data collection. MZ, AM, ER : contributed to collected all of samples. MZ, RSH: contributed to study design and manuscript drafting. All authors approved the final version of manuscript.

Funding/Support

The budget for this research has been provided by the members of the research team and also was supported by Shahrekord University of Medical Sciences and Food and Drug Control Laboratory of Shahrekord

Acknowledgements

This article was obtained from a research project approved by Shahrekord Branch, Islamic Azad University (approval no: 13350403962023). The authors wish to thank Shahrekord Branch, Islamic Azad University, Shahrekord University of Medical Sciences and Food and Drug Control Laboratory of Shahrekord for their support.

\section{References}

1. de Araújo Siqueira Bento W, Lima BP, Paim APS. Simultaneous determination of synthetic colorants in yogurt by HPLC. Food Chem. 2015;183:154-60. doi: 10.1016/j. foodchem.2015.03.050.

2. Khorshidi N, Niazi A. A novel ion pair based surfactant assisted microextraction modified by orthogonal signal correction partial least squares for determination of food dyes. J Food Meas Charact. 2018;12(3):1885-95. doi: 10.1007/s11694018-9802-8.

3. Rovina K, Prabakaran PP, Siddiquee S, Shaarani SM. Methods for the analysis of sunset yellow FCF (E110) in food and beverage products- a review. TrAC Trend Anal Chem 2016;85 Pt B:47-56. doi: 10.1016/j.trac.2016.05.009.

4. Prado MA, Godoy HT. Artificial food coloring. Braz J Food Nut. 2003;14(2):237-50.

5. Institute of Standards and Industrial Research of Iran (ISIRI). Permitted food additives-food color-list and general specifications. 5th ed. ISIRI; 2013.

6. Chao M, Ma X. Convenient electrochemical determination of sunset yellow and tartrazine in food samples using a poly $(\mathrm{L}-$ phenylalanine)-modified glassy carbon electrode. Food Anal Methods. 2015;8(1):130-8. doi: 10.1007/s12161-014-9879-6.

7. Tsai CF, Kuo CH, Shih DYC. Determination of 20 synthetic dyes in chili powders and syrup-preserved fruits by liquid chromatography/tandem mass spectrometry. J Food Drug Anal. 2015;23(3):453-62. doi: 10.1016/j.jfda.2014.09.003.

8. Dorraji PS, Jalali F. Electrochemical fabrication of a novel $\mathrm{ZnO} /$ cysteic acid nanocomposite modified electrode and its 
application to simultaneous determination of sunset yellow and tartrazine. Food Chem. 2017;227:73-7. doi: 10.1016/j. foodchem.2017.01.071.

9. Yilmaz UT, Ergun F, Yilmaz H. Determination of the food dye carmine in milk and candy products by differential pulse polarography. J Food Drug Anal. 2014;22(3):329-35. doi: 10.1016/j.jfda.2013.12.002.

10. Liu FJ, Liu CT, Li W, Tang AN. Dispersive solid-phase microextraction and capillary electrophoresis separation of food colorants in beverages using diamino moiety functionalized silica nanoparticles as both extractant and pseudostationary phase. Talanta. 2015;132:366-72. doi: 10.1016/j.talanta.2014.09.014.

11. Yi J, Zeng L, Wu Q, Yang L, Xie T. Sensitive simultaneous determination of synthetic food colorants in preserved fruit samples by capillary electrophoresis with contactless conductivity detection. Food Anal Methods. 2018;11(6):160818. doi: 10.1007/s12161-017-1141-6.

12. Minioti KS, Sakellariou CF, Thomaidis NS. Determination of 13 synthetic food colorants in water-soluble foods by reversedphase high-performance liquid chromatography coupled with diode-array detector. Anal Chim Acta. 2007;583(1):103-10. doi: 10.1016/j.aca.2006.10.002.

13. de Andrade FI, Florindo Guedes MI, Pinto Vieira Í G, Pereira Mendes FN, Salmito Rodrigues PA, Costa Maia CS, et al. Determination of synthetic food dyes in commercial soft drinks by TLC and ion-pair HPLC. Food Chem. 2014;157:1938. doi: 10.1016/j.foodchem.2014.01.100.

14. Kiseleva MG, Pimenova VV, Eller KI. Optimization of conditions for the HPLC determination of synthetic dyes in food. J Anal Chem. 2003;58(7):685-90. doi: 10.1023/a:1024716322120.

15. Purba NBR, Rohman A, Martono S. Validation and application of reversed-phase high-performance liquid chromatography for quantitative analysis of acid orange 7 and Sudan II in blusher products. J Appl Pharm Sci. 2019;90(7):100-5. doi: 10.7324/japs.2019.90714.

16. Alp H, Başkan D, Yaşar A, Yaylı N, Ocak Ü, Ocak M. Simultaneous determination of sunset yellow FCF, allura red AC, quinoline yellow WS, and tartrazine in food samples by RP-HPLC. J Chem. 2018;2018:6486250. doi: 10.1155/2018/6486250.

17. Kucharska M, Grabka J. A review of chromatographic methods for determination of synthetic food dyes. Talanta. 2010;80(3):1045-51. doi: 10.1016/j.talanta.2009.09.032.

18. Yamjala K, Nainar MS, Ramisetti NR. Methods for the analysis of azo dyes employed in food industry--a review. Food Chem. 2016;192:813-24. doi: 10.1016/j.foodchem.2015.07.085.

19. International Conference on Harmonization $(\mathrm{ICH})$ of Technical Requirements For Registration Of Pharmaceuticals For Human Use .Validation of Analytical Procedures: Text and Methodology Q2 (R1);2005:13-14. https://www.ema.europa. eu/en/documents/scientific-guideline/ich-q-2-r1-validationanalytical-procedures-text-methodology-step-5_en.pdf

20. Sampling and sample preparation catalogue. Available from: https://www.affinisep.com. Technical and customer support. technical support.2014.

21. Yoshioka N, Ichihashi K. Determination of 40 synthetic food colors in drinks and candies by high-performance liquid chromatography using a short column with photodiode array detection. Talanta. 2008;74(5):1408-13. doi: 10.1016/j. talanta.2007.09.015.

22. Rejczak T, Tuzimski T. Application of high-performance liquid chromatography with diode array detector for simultaneous determination of 11 synthetic dyes in selected beverages and foodstuffs. Food Anal Methods. 2017;10(11):3572-88. doi: 10.1007/s12161-017-0905-3.

23. Floriano L, Ribeiro LC, Sabit N, Banderia NMG, Prestes OD, Zanella R. Determination of six synthetic dyes in sports drinks by dispersive solid-phase extraction and HPLC-UV-Vis. J Braz Chem Soc. 2018;29(3):602-8. doi: 10.21577/01035053.20170173.

24. Zamani Mazdeh F, Rajabi Khorrami A, Moradi-Khatoonabadi Z, Esmaeili Aftabdari F, Shams Ardekani MR, Moghaddam $\mathrm{GH}$, et al. Determination of 8 synthetic food dyes by solid phase extraction and reversed-phase high performance liquid chromatography. Trop J Pharm Res. 2016;15(1):173-81. doi: 10.4314/tjpr.v15i1.24.

25. Feng F, Zhao Y, Yong W, Sun L, Jiang G, Chu X. Highly sensitive and accurate screening of 40 dyes in soft drinks by liquid chromatography-electrospray tandem mass spectrometry. J Chromatogr B Analyt Technol Biomed Life Sci. 2011;879(20):1813-8. doi: 10.1016/j.jchromb.2011.04.014.

26. Faraji M, Nasiri Sahneh B, Javanshir R. An Ion-pair dispersive liquid-liquid microextraction for simultaneous determination of synthetic dyes in ice cream samples by HPLC. Anal Bioanal Chem Res. 2017;4(2):213-25. doi: 10.22036/ abcr.2017.70877.1129.

27. Institute of Standards and Industrial Research of Iran (ISIRI). Specification and methods of test for fruit snack (fruit paste). 2th ed. ISIRI; 2005.

28. Amini Kadijani P, Faraji M, Salami M. Development and validation of dispersive liquid-liquid microextraction coupled to spectrophotometry for extraction and determination of carmoisine in foodstuff. Iranian Journal of Nutrition Sciences \& Food Technology. 2016;11(1):95-106. [Persian].

29. Mohammadi H, Vahedi S, Hajimahmoodi M, Nadjarian A, Salsali M, Shokrzadeh M. A Survey on the Use of Synthetic and Natural Fruit Colures in non-certified Juice and Fruit Products in Tehran, Iran. Journal of Mazandaran University of Medical Sciences. 2015;24(120):159-72. [Persian].

30. Institute of Standards and Industrial Research of Iran (ISIRI). Edible Ices Products-Specification. With No 3964. ISIRI; 2007.

31. European Union (EU). Regulation (EU) No $94 / 36$ of the European Parliament and of the Council of 30 June 1994 on colors for use in foodstuffs. Official Journal of the European Union L. 1994;237(11):13-28.

32. Rao P, Bhat RV, Sudershan RV, Krishna TP, Naidu N. Exposure assessment to synthetic food colours of a selected population in Hyderabad, India. Food Addit Contam. 2004;21(5):415-21. doi: 10.1080/02652030410001668772.

33. Yuet-Wan Lok K, Chung WY, Benzie IF, Woo J. Colour additives in snack foods consumed by primary school children in Hong Kong. Food Addit Contam Part B Surveill. 2010;3(3):148-55. doi: 10.1080/19393210.2010.509815. 